\title{
Resenha: A Paixão Perigosa: Por Que o Ciúme é Tão Necessário Quanto o Amor e o Sexo
}

\author{
André Luiz Moraes Ramos ${ }^{1}$ \\ Universidade do Vale do Itajaí \\ Centro Universitário Salesiano de São Paulo \\ Marco Calegaro \\ Universidade do Vale do Itajaí \\ Universidade Regional de Blumenau

\section{Book Review: The Dangerous Passion: Why Jealousy is as Necessary as Love and Sex}

Buss, D. M. (2000). Os perigos da paixão: Por que o ciúme é tão necessário quanto o amor e o sexo. (M. Campello, Trad.) Rio de Janeiro: Objetiva.

David Buss tem-se tornado o mais expressivo e carismático psicólogo evolucionário no estudo das diferenças de gênero entre homens e mulheres, produzindo livros e artigos científicos que tiveram grande repercussão na década de 90. Em A Paixão Perigosa, título traduzido por Myriam Campello para The dangerous passion, Buss, finalmente, reúne as contribuições de uma década de pesquisas numa obra em que apresenta uma síntese da psicologia evolucionária sobre os relacionamentos entre homens e mulheres, em especial o ciúme sexual.

Homens e mulheres desenvolveram diferentes estratégias para lidar com o problema da sobrevivência e da reprodução. Os homens, para se certificarem de que os filhos gerados num relacionamento são verdadeiramente seus, o que tem conseqüências substanciais para a sua auto-estima, têm o seu ciúme motivado pela suspeita de infidelidade sexual de sua mulher. Já elas, diante do temor de que o seu companheiro possa se envolver emocionalmente com uma rival, a ponto de dirigir seus investimentos materiais, afetivos e financeiros para esta pessoa, desenvolveram o ciúme como uma resposta apropriada para a manutenção deste relacionamento.

Partindo deste mote, Buss analisa nesta obra as múltiplas facetas do ciúme, tais como o seu aspecto paradoxal, no qual ao mesmo tempo em que visa proteger o amor é capaz de destruir um relacionamento; as diferenças psicológicas entre o ciúme de homens e mulheres; a chamada Síndrome de Otelo, citando casos clínicos em que o ciúme sinaliza uma infidelidade real ou potencial; aborda os comportamentos abusivos produzidos pela paixão perigosa; as características que tornam as pessoas susceptíveis à infidelidade; investiga porque as mulheres traem; analisa as estratégias para

1 Endereço: Rua Prof. Antônio Azevedo de Castilho, 337. Bairro Jardim Nova Lorena. Lorena - SP. CEP: 12.602-360.

E-mail: andre.lmr@uol.com.br enfrentar o ciúme e a infidelidade; e finaliza o livro com os usos positivos do ciúme para realçar a paixão.

Juntamente com Jealousy organizado por Clanton e Smith (1977), Jealousy: Theory, research, and clinical strategies de White e Mullen (1989), The psychology of jealousy end envy editado por Salovey (1991), Jealousy: The psychological data escrito por Mathes (1992) e, mais recentemente, Romantic Jealousy: Causes, symptoms, cures de Pines (1998), com certeza este livro já se tornou uma referência no estudo do ciúme.

Diferente de suas obras anteriores de sucesso, The evolution of desire: Strategies of human mating (1994) e Evolucionary psychology: The new science of the mind (1999), que foram dirigidas à comunidade científica, desta vez David Buss optou por popularizar ainda mais as idéias da teoria evolucionária, ampliando o universo de leitores para muito além da academia. Para tanto adotou estratégias bem definidas, quanto ao estilo redacional, o título do livro e escolheu a dedo a data do seu lançamento.

Sua linguagem é ágil, utiliza-se de bastantes exemplos da vida diária e adota o sistema de fazer citações de autores através de números sobrescritos, tornando a leitura fluente e de fácil compreensão para o público leigo, mas um tanto enfadonha para os pesquisadores no assunto, que para saberem detalhes sobre quem está sendo citado precisam consultar primeiro a lista de notas e depois as referências bibliográficas, que estão no final da obra.

No título foram intencionalmente escolhidas e ordenadas cinco expressões provocativas: paixão, perigo, ciúme, amor e sexo, todas extremamente carregadas de significado afetivo, criando ao redor do livro um clima de sensacionalismo capaz de instigar o leitor e atrair a sua atenção para a obra.

Seu lançamento nos Estados Unidos ocorreu, não casualmente, no dia dos namorados, o Valentine's Day, para ter o impacto que a obra tencionava, o que não deixa de ser uma potente estratégia de marketing.

Uma pessoa ciumenta, ao ler este livro, tem uma grande probabilidade de se sentir reconfortada, encontrando ali um alívio para este seu sentimento. O ciúme é tratado como uma 
resposta defensiva e protetora frente a ameaças à auto-estima e ao relacionamento, denotando, assim, uma impressionante sabedoria emocional. Há inclusive a citação de diversos casos em que os ciumentos foram em princípio diagnosticados como patológicos-delirantes e que posteriormente suas suspeitas foram confirmadas através de evidências inequívocas da infidelidade de seu par, numa sutil indicação de que mesmo casos extremos de ciúme são positivos segundo a óptica evolucionária. Nestes termos, esta visão pode ser perigosa para aquelas pessoas que se sentirem estimuladas a serem ainda mais ciumentas como uma demonstração de prudência adaptativa. Ademais, deve-se ressaltar que a literatura psiquiátrica é pródiga em casos patológicos devidamente diagnosticados como transtorno paranóide-delirante em que o ciúme é um dos sintomas identificados, o que o texto não se preocupa em dar o merecido destaque.

A Psicologia Evolucionária analisa os relacionamentos entre homens e mulheres a partir da relação indissociável entre sexo e procriação. Assim sendo, uma pessoa bem sucedida é aquela capaz de perpetuar o seu material genético através da reprodução e da sobrevivência de seus filhos e o seu ciúme é um mecanismo de defesa desenvolvido para esta empreitada. Deste modo, o ciúme é enfocado a partir de uma visão sexista, pois considera que a evolução moldou padrões diferenciados para homens e mulheres, segundo os quais eles desenvolveram o ciúme como resposta à infidelidade sexual e elas contra a infidelidade emocional. Os dados mais otimistas que apóiam esta diferenciação foram obtidos em 2 a cada 3 casos pesquisados em ambos os sexos e os sujeitos que compõem o terço restante tenderão ao fracasso evolucionário.

Com base na consistência dos resultados das pesquisas com amostras de 37 países de seis continentes, Buss afirma que os dados são conclusivos (p. 73) e, como conseqüência, as diferenças entre os sexos são universais (p. 74).

Entretanto, os dados sobre as diferenças de gênero no ciúme citados por David Buss não são os únicos encontrados na literatura científica. A seletividade perceptiva do autor fez com que ele mencionasse em seu livro apenas as pesquisas que apóiam a perspectiva evolucionária e desprezasse toda uma produção significativa a favor de perspectivas contrárias, seja através da minimização do seu valor, como fez com Hupka (1991) e DeSteno e Salovey (1995, 1996), ou mesmo da mera negação da existência de outros estudos.

Não foi citado o trabalho de Hupka e Bank (1996) que, adotando uma interpretação sociocultural corroborada por numerosos estudos etnográficos (Hupka, 1981; Clanton, 1989; Hupka \& Ryan 1990), utilizou as perspectivas do construtivismo social de e do papel social para explicar as diferenças de gênero em função de normas culturais e não como diferenças sexuais inatas. Sequer consta nas referências bibliográficas o excelente artigo de Pines e Friedman (1998), apresentando uma série de estudos com diferentes metodologias em que os dados foram melhor explicados pela teoria sociocultural. Há, ainda, outros autores ignorados como Christine Harris, que tem divulgado dados que demonstram a não superação de uma teoria sobre a outra, ora a favor da perspectiva evolucionária ora da perspectiva sociocultural (Harris \& Christenfeld, 1996a, 1996b; Harris, Olthof, Terwogt \& Hardman, 1987).

Como demonstram estes dados, não há, no momento, base suficiente para afirmar, como faz David Buss em A paixão perigosa, que explicações contrárias à evolucionária constituam-se em mitos sobre o ciúme, pois estas discordam dos fatos conhecidos (p. 43). A busca de padrões universais faz com que, em certos momentos, o autor apare as arestas da realidade para que os seus dados se encaixem na sua teoria de forma elegante. Na verdade, evidências de lado a lado fazem com que os estudos sobre o ciúme recebam um impulso ainda maior, tornando este um campo profícuo para novas investigações, que se utilizem de perspectivas teórico-conceituais e metodológicas diversificadas.

Portanto, A paixão perigosa é uma contribuição indispensável para a compreensão do ciúme, que, num estilo envolvente e sedutor, apresenta as idéias evolucionárias a respeito deste sentimento. No entanto, esta não é, com certeza, a obra conclusiva sobre o ciúme sexual como pretendia David Buss e, para se adquirir um conhecimento mais completo sobre este tema, é recomendável a leitura dos outros textos, como os citados nesta resenha.

\section{Referências}

Buss, D.B. (1994). The evolution of desire: Strategies of human mating. New York: Basic Books.

Buss, D.M. (1999). Evolucionary psychology: The new science of the mind. Boston: Allyn \& Bacon.

Clanton, G. (1989). Jealousy in America, 1945-1985. Em D.D. Franks \& E.D. McCarthy (Eds.), The sociology of emotions (pp. 179-193). Greenwich, CT: JAI Press.

Clanton, G. \& Smith, L. G. (1977). Jealousy. New York: PrenticeHall.

De Steno, D.A. \& Salovey, P. (1995). Jealousy end envy. Em A.S.R. Manstead \& M. Hewstone (Eds.), The Blackwell encyclopedia of social psychology. Oxford: Basic Blackwell.

De Steno, D.A. \& Salovey, P. (1996). Evolucionary origins of sex differences in jealousy?: Questioning the "fitness" of the model. Psychology Science, 7, 367-372.

Harris, C.R. \& Christenfeld, N. (1996a). Gender, jealousy, and reason. Psychological Science, 7, 364-366.

Harris, C.R. \& Christenfeld, N. (1996b). Jealousy and rational responses to infidelity across gender and culture. Psychological Science, 7, 378-379.

Harris, C.R., Olthof, T.J., Terwogt, M.M. \& Hardman, C.E. (1987). Children's knowledge of the situations that provoke emotion. International Journal of Behavioral Development, 10, 319-343.

Hupka, R.B. (1981). Cultural determinants of jealousy. Alternative Lifestyles, 4, 310-356.

Hupka, R.B. (1991). The motive for arousal of romantic jealousy: Its cultural origin. Em P. Salovey (Ed.), The psychology of jealousy and envy (pp. 252-270). New York: Guilford Press.

Hupka, R.B. \& Bank, A.L. (1996). Sex differences in jealousy: Evolution or social construction? Cross-Cultural Research, 30, 24-59. 
Hupka, R.B. \& Ryan, J.M. (1990). The cultural contribution to jealousy: Cross-cultural aggression in sexual jealousy situations. Behavior Science Research, 24, 51-71.

Mathes, E.W. (1992). Jealousy: The psychological data. New York: University Press of America.

Pines, A. (1998). Romantic Jealousy: Causes, symptoms. New York: Routledge.
Pines, A. \& Friedman, A. (1998). Gender differences in romantic jealousy. Journal of Social Psychology, 138, 54-71.

Salovey, P. (1991). The psychology of jealousy and envy. New York: Guilford Press.

White, G.L \& Mullen, P.E. (1989). Jealousy: Theory, research, and clinical strategies. New York: The Guilford Press.

Recebido em 25.10.2001

Primeira decisão editorial em 26.11.2001

Versão final em 07.01.2002

Aceito em 17.01.2002

\section{Subscriptions}

Send your order for Subscriptions to the Psicologia: Teoria e Pesquisa to:

Revista Psicologia: Teoria e Pesquisa

Secretaria de Divulgação

Universidade de Brasília - Instituto de Psicologia

70910-900 Brasília - DF

BRAZIL

Rate for individuals US\$ 48

Rate for institutions US\$ 75

Past single numbers:

US\$ 14 (individual subscriber)

US\$ 20 (institutional subscriber)

US\$ 24 (not individual subscriber)

US\$ 37 (not institutional subscriber) 